\title{
EE-4A Regimen
}

National Cancer Institute

\section{Source}

National Cancer Institute. EE-4A Regimen. NCI Thesaurus. Code C67293.

A regimen consisting of vincristine and dactinomycin, administered after nephrectomy and used for the treatment of limited-stage Wilm's tumor with a favorable histology, including focal anaplastic disease. 